\title{
Antioxidant enzymes and vascular diseases
}

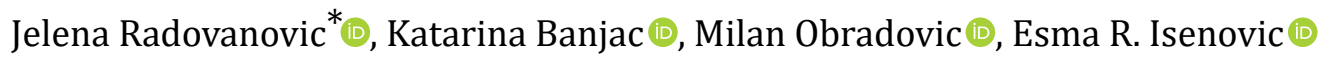 \\ Department of Radiobiology and Molecular Genetics, "VINČA” Institute of Nuclear Sciences-National Institute of the Republic of \\ Serbia, University of Belgrade, 522 Belgrade, Serbia
}

*Correspondence: Jelena Radovanovic, Department of Radiobiology and Molecular Genetics, "VINČA" Institute of Nuclear Sciences-National Institute of the Republic of Serbia, University of Belgrade, 522 Belgrade, Serbia. jelenarad89@gmail.com

Academic Editor: Akiko Mammoto, Medical College of Wisconsin, USA

Received: October 27, 2021 Accepted: December 2, 2021 Published: December 31, 2021

Cite this article: Radovanovic J, Banjac K, Obradovic M, Isenovic ER. Antioxidant enzymes and vascular diseases. Explor Med. 2021;2:544-55. https://doi.org/10.37349/emed.2021.00070

\begin{abstract}
Reactive oxygen species (ROS) and reactive nitrogen species (RNS) play a fundamental role in regulating endothelial function and vascular tone in the physiological conditions of a vascular system. However, oxidative stress has detrimental effects on human health, and numerous studies confirmed that high ROS/ RNS production contributes to the initiation and progression of cardiovascular diseases. The antioxidant defense has an essential role in the homeostatic functioning of the vascular endothelial system. Endogenous antioxidative defense includes various molecules and enzymes such as superoxide dismutase, catalase, glutathione reductase, and glutathione peroxidase. Together all these antioxidative enzymes are essential for defense against harmful ROS features. ROS are mainly generated from redox-active compounds involved in the mitochondrial respiratory chain. Thus, targeting antioxidative enzymes and mitochondria oxidative balance may be a promising approach for vascular diseases occurrence and treatment. This review summarized the most recent research on the regulation of antioxidative enzymes in vascular diseases.
\end{abstract}

\section{Keywords}

Reactive oxygen species, reactive nitrogen species, oxidative stress, antioxidant enzymes, vascular diseases

\section{Introduction}

Cardiovascular disease (CVD) is the leading cause of mortality and morbidity worldwide, including a wide array of disorders-cardiac muscle diseases and diseases of the vascular system supplying the heart, brain, and other vital organs [1]. There is significant evidence that vascular oxidative stress (OxS) is the leading cause of CVD [2,3]. OxS is a harmful consequence of the imbalance between production and removal of reactive oxygen species (ROS) and reactive nitrogen species (RNS) in situations where biological systems in cells and tissues cannot detoxify these reactive products [4-7]. ROS and RNS are small reactive ions and molecules that are derived from oxygen metabolism [8-10]. Small amounts of ROS and RNS are constantly produced and involved in defense mechanisms against microorganisms [11]. High doses of ROS/RNS cause oxidative modifications of major cell macromolecules (lipids, proteins, carbohydrates, and DNA), which can be further used as markers of OxS $[12,13]$. ROS plays an essential role in regulating endothelial 
function and vascular tone [4] in promoting systemic inflammation, endothelial dysfunction, and vascular remodeling [2,4]. Additionally, superoxide anion $\left(\mathrm{O}_{2}^{-}\right)$interacts with nitric oxide (NO), producing highly toxic peroxynitrite (ONOO-) and therefore decreasing $\mathrm{NO}$ availability for smooth muscle relaxation function $[14,15]$. All these processes lead to vascular system diseases such as atherosclerosis and arterial hypertension [1]. Cellular homeostasis is essential for preventing $0 \mathrm{xS}$, and it is finely tuned through the expression and action of antioxidant enzymes and non-enzymatic mechanisms [16]. Cells contribute to antioxidant defense in the vascular wall through numerous antioxidant enzymes such as superoxide dismutases [manganese superoxide dismutase (MnSOD), copper-zinc SOD (CuZnSOD), extracellular superoxide dismutase (EcSOD)], catalase (CAT), glutathione (GSH) peroxidase (GPx), thioredoxin peroxidase, and heme oxygenases [2]. The principal intracellular antioxidant is GSH, which can scavenge ROS and RNS, and additionally, GSH can also indirectly perform antioxidant function acting as a cofactor for various enzymes [17]. Regarding non-enzymatic antioxidants, the most potent ones are vitamin A, vitamin C, bilirubin, $\alpha$-tocopherol (vitamin E), and $\beta$-carotene, which are present in blood $[2,11]$.

\section{Search strategy}

Data used for this review are obtained by searching the electronic database [PUBMED/MEDLINE 1988-October 2021]. The main data search terms were: reactive oxygen species, reactive nitrogen species, 0xS, antioxidant enzymes, vascular diseases, antioxidant enzymes and vascular diseases, cardiovascular disease, metabolic syndrome, mitochondrial chain, nicotinamide adenine dinucleotide phosphate $[\mathrm{NAD}(\mathrm{P}) \mathrm{H}]$, and xanthine oxidases. Additionally, abstracts from national and international diabetes and cardiovascular-related meetings were searched.

\section{Antioxidant enzymes}

In physiological conditions, enzymatic and non-enzymatic antioxidant systems maintain an equilibrium between the production and neutralization of ROS and RNS [11]. Antioxidant enzymes lower ROS and RNS levels or counteract downstream cellular effects of excessive oxidation. In addition, antioxidant enzymes detoxify ROS/RNS into less reactive species serving as an intermediate defense against ROS/RNS [18]. The primary antioxidant enzymes are SOD, CAT, GPx, and GSH reductase (GR) $[12,18]$. Highly reactive radical $\mathrm{O}_{2}$ is converted by SOD to the less reactive radical hydrogen peroxide $\left(\mathrm{H}_{2} \mathrm{O}_{2}\right)$, which can further be dissolved by CAT or GPx [18].

\section{Superoxide-dismutases}

Superoxide-dismutase is a group of metalloenzymes that have a major antioxidant role in human health. In humans, there are three types of SODs: cytosolic CuZn (SOD1), mitochondrial Mn (SOD2), and extracellular CuZn (SOD3, EcSOD) [18, 19]. Phylogenetic analysis of SOD genes in vertebrates showed homology between SOD1 and SOD3 genes. However, the similarity with the SOD2 gene was shown to be minimal [20]. Moreover, SODs are presented as the first and the most major line of antioxidant defense against ROS, particularly $\mathrm{O}_{2}^{-}[19,20]$. The reaction implies binding $\mathrm{O}_{2}^{-}$to an oxidized form of the enzyme $\left(\mathrm{Fe}^{3+}, \mathrm{Cu}^{2+}\right.$, and $\mathrm{Mn}^{3+}$ respectively), which results in acquiring a proton and releasing molecular oxygen. Furthermore, second $\mathrm{O}_{2}^{-}$and proton bind to the reduced form of the enzyme $\left(\mathrm{Fe}^{2+}, \mathrm{Cu}^{+}\right.$, and $\left.\mathrm{Mn}^{2+}\right)$, which results in liberating $\mathrm{H}_{2} \mathrm{O}_{2}$ and returning of enzyme to its oxidized form $[19,21]$. All three forms of SODs contain specific metals, which are essential for their function. SOD1 and SOD3 contain $\mathrm{Cu}$ and $\mathrm{Zn}$ ions in their catalytic center, while SOD2 contains Mn ions in their catalytic center [18]. SOD1 is a highly abundant enzyme that is ubiquitously expressed in eukaryotes, and it has been found in the cytoplasm, nuclear compartments, lysosomes, and mitochondrial compartments of mammalian cells [20]. Studies with SOD1 male and female knockout animals suggested that SOD1 is located in the mitochondrial intermembrane space, which is fundamental for motor axon maintenance. In contrast, mutations of the SOD1 gene that result in various single amino acids have been linked to familial amyotrophic lateral sclerosis $[20,22]$. SOD2 is a tetramer enzyme located in mitochondria within the mitochondrial matrix, the main leading free radical production site from the electron transport chain [23]. Thus, SOD2 is a primary antioxidant enzyme in mitochondria essential for protecting respiring 
cells from oxidative damage [24]. Studies have shown that SOD2 knockout male mice die 2-3 weeks after birth due to cardiomyopathy and neurodegenerative diseases [20,25]. Although there is substantial evidence supporting the idea of biochemical defects in the mitochondria in Parkinson's and Alzheimer's disease, there is little evidence to suggest the direct involvement of SOD2 in the clinical progression of the diseases [23]. Concerning SOD3, it contains a signal peptide that leads this enzyme to extracellular spaces, and it is probably located along the whole depth of the vascular wall $[20,26]$. SOD3 is highly restricted to the specific cell types and tissue where it can exceed the activity of SOD1 and SOD2 [20,26].

\section{CAT}

CAT exists as a tetramer enzyme that consists of four polypeptide chains with four ferriprotoporphyrin prosthetic groups per molecule [11]. CATs react with $\mathrm{H}_{2} \mathrm{O}_{2}$, breaking it down into molecular oxygen and water. Since one molecule of CAT hydrolyses over a million molecules of $\mathrm{H}_{2} \mathrm{O}_{2}$ per second, it is considered a highly effective enzyme [11,27]. CATs are found in a wide range of aerobic and anaerobic organisms and are divided into three groups based on their structure and function $[27,28]$. The first and the second groups are heme-containing enzymes called typical CAT and CAT peroxidases, whereby the third group contains Mn ions in their catalytic center and are called Mn CAT [28]. Numerous studies detected CAT gene mutations in patients with diabetes mellitus, hypertension, and vitiligo [29].

\section{GPx and GSH reductase}

GPxs are enzymes that catalyze the reduction of $\mathrm{H}_{2} \mathrm{O}_{2}$ to water or hydroperoxides to corresponding alcohols using reduced GSH [30]. This reaction involves the formation of a disulfide bridge between two GSH molecules, creating a GSH disulfide, an oxidized version of GSH $\left(_{2} \mathrm{O}_{2}+2 \mathrm{GSH} \rightarrow\right.$ oxidized glutathione (GS-SG) $+2 \mathrm{H}_{2} \mathrm{O}$ ) [30,31]. When the GSH molecule receives one electron from ROS, it becomes reactive, especially towards thiols, whereas the most abundant thiols in the cells are usually other GSH molecules, so dimer formation is favored [31]. Furthermore, recycling oxidized GSH back to its reduced form is catalyzed by enzyme GR, whereby this reaction requests the involvement of flavin adenine dinucleotide (FAD) and reduces $\mathrm{NAD}(\mathrm{P}) \mathrm{H}[31]$.

In mammalian tissues, there are four major GPx isozymes with selenocysteine in their active sites and two isozymes that are closely related to GPx3 [30,32]. Their expression is tissue-dependent, whereas GPx1 is found in red cells, liver, lung, and kidney, GPx2 is found in gastrointestinal tracts, GPx3 is present in different organs such as kidney, lung, epididymis, vas deferens, placenta, seminal vesicle, heart and muscle and GPx4 which is widely distributed in various tissues [30]. GPx5 is found in the epididymis and lacks the inactive selenocysteine, while GPx6 is located in the olfactory epithelium [30]. Their subcellular locations are present in cytosol, nucleus, mitochondria and bound to membranes [30,31]. Moreover, GR activity is also present in cytosol, nucleus, and mitochondria, and GR is found in the endoplasmic reticulum and the lysosomes [31].

\section{OxS and vascular diseases}

ROS have physiological and pathological implications in cardiovascular tissues [33]. Low amounts of ROS generation are essential for cell functioning/signaling and, this process is called redox signaling [34, 35]. Also, subcellular ROS is significant for tissue adjustment to injury [36]. Various molecules participate in redox signaling, including hydroxyl radical $(\mathrm{OH}), \mathrm{H}_{2} \mathrm{O}_{2}$, transcription factors, $\mathrm{NO}, \mathrm{O}_{2}$; and all manifest protective actions in vascular physiology function [4,33]. As far as cellular signaling, ROS alter cell signal pathway, gene expression, cellular proliferation, and protection versus infections [4]. In respect of vascular physiology, ROS may influence endothelium, cell differentiation and migration, vascular tone, and NO suppression [4]. However, in pathological states, ROS can induce oxidative disbalance of all cell components, along with proteins, lipids and nucleic acids [4, 37]. Thus, OxS is remarkably involved in heart failure and myocardial infarction development (Figure 1) [33].

Chronically increased levels of ROS may participate in endothelial and mitochondrial dysfunction, atherosclerosis, hypertension development, and cardiomyocytes hypertrophy [33]. Enzymatically, $\mathrm{O}_{2}^{-}$is mainly generated through the medium of NAD(P)H and xanthine oxidase (XO) [1]. NAD(P)H and XO oxidase 
are the primary molecules in the ROS pathology of vascular diseases [4]. Activated XO may attach to vascular cells and causes NO reduction and ONOO- escalation [38]. Further, increased XO activity may be essential for metabolic syndrome development since it generates $\mathrm{O}_{2}{ }^{-}$and reduces SOD activity, leading to endothelial dysfunction [39]. NAD(P)H oxidase is a pro-oxidant enzyme complex that generates $\mathrm{H}_{2} \mathrm{O}_{2}$ and $\mathrm{O}_{2}$ - through $N A D(P) H$ genes, which create the transmembrane proteins responsible for electron transport [40, 41]. Various $\mathrm{NAD}(\mathrm{P}) \mathrm{H}$ isoforms are expressed in human vascular smooth muscle cells (VSMCs) and endothelium, such as NOX1, NOX2, NOX4, and NOX5 [42]. This enzyme induces OxS which is associated with various pathologies, such as hypertension, coronary artery disease, atherosclerosis, diabetes mellitus, etc. [40, 43-45].

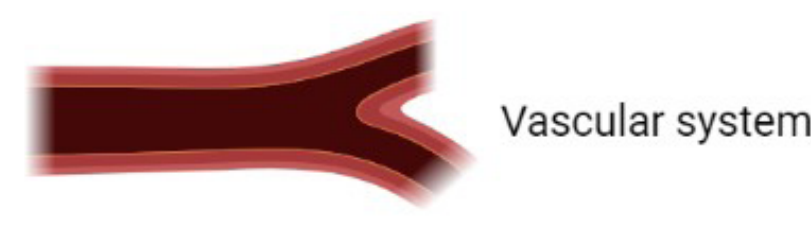

Physiological conditions

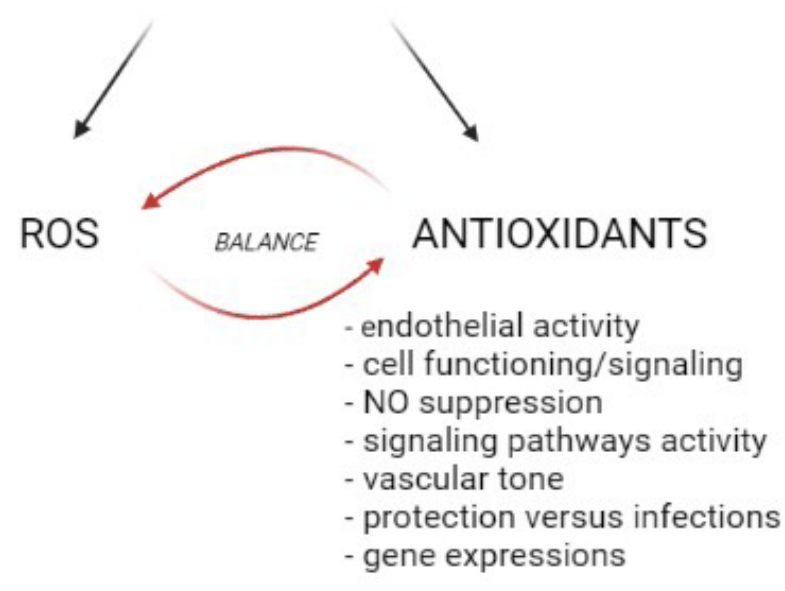

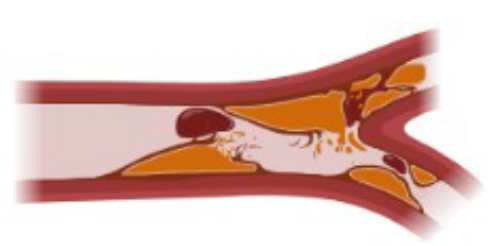

Pathological conditions

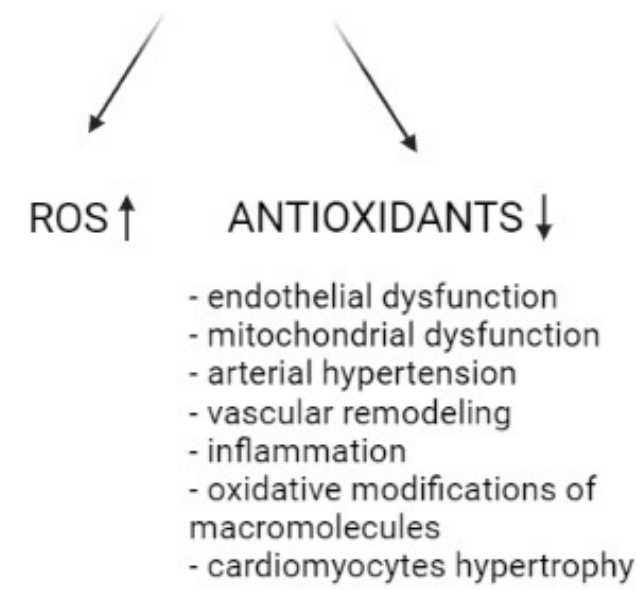

Figure 1. The impact of disbalance between ROS/RNS and antioxidant enzymes in OxS development in vascular diseases. It was created with Biorender.com

Targeting distinct agents which are responsible for $0 \mathrm{xS}$ in vascular tissues seems to be a promising therapeutic approach [42]. According to a newly updated cohort study, the application of XO inhibitor is positively correlated with the decreased risk of vascular diseases in male and female human patients [46]. Further, using an in silico approach, some authors present new NAD(P)H inhibitors for hypertension treatment [47]. Hence, the management of NAD(P)H and XO oxidases and their inhibitors expressed in the VSMCs might be a potential target for vascular diseases medication that would inhibit the only pathological activity of $\mathrm{NAD}(\mathrm{P}) \mathrm{H}[40,42,48]$. The endothelium is essential for vascular homeostasis and blood fluidity, and vascular tone balance [49]. In the endothelial cells, NO has a vital role in the proportion of vascular homeostasis. Since excessive ROS causes NO bioactivity reduction, endothelial dysfunction directly affects vascular blood vessels $[49,50]$. Decreased NO generation occurs due to reaction with $\mathrm{O}_{2}$; produced from $\mathrm{NAD}(\mathrm{P}) \mathrm{H}$ and $\mathrm{XO}$ oxidase, and consequently, ONOO- originates, leading to apoptosis of endothelial cells $[49,51,52]$.

However, some authors point out some positive aspects of small ROS amount in endothelial cell generation and metabolism [53]. Endothelial cells can generate ATP in anaerobic conditions and store oxygen, and this paradox brings decreased ROS levels and rapid ATP generation [53]. Nonenzymatically, $\mathrm{O}_{2}{ }^{-}$is generated when oxygen reacts with redox-active compounds [1], especially from the mitochondrial respiratory chain (dominant source of intracellular ROS) [33]. Mitochondria are especially abundant in cardiac tissue [49]. Thus, increased ROS generation in the course of mitochondrial dysfunction is an essential factor for the occurrence and development of atherosclerosis, high blood pressure, heart failure, and ischemia-reperfusion injury [54]. For instance, one study with a male murine model of myocardial 
infarction induced by coronary ligation, $\mathrm{OH}$, and lipide peroxide values in the mitochondria was elevated [55]. Besides, ROS generated in mitochondria is related to vascular complications in diabetes, especially cardiomyopathy $[54,56]$. According to new data, in male Wistar rats with induced diabetes, a significant increase of ROS and decrease of CAT activity has been recorded in the heart muscle [57]. In the same study, mitochondrial complexes I, II, III, and IV were reduced, and SOD2 and GSH/glutathione disulfide (GSSG) ratio values decreased in heart mitochondria in diabetic rats [57]. Regarding mitochondrial ROS participation in vascular disease pathogenesis, targeting mitochondria and their oxidative balance may be a promising approach for vascular complications medication.

\section{Role of antioxidant enzymes in vascular diseases}

A protective system for free radical excess removal is generated during the evaluation, whereas all antioxidants represent an antioxidant defensive system [58]. Antioxidants are divided into two groups: enzymes, the primary line of antioxidative defense (SOD, CAT, GPx, GR, GSH) and non-enzymes, the secondary line of antioxidative defense (vitamins $\mathrm{E}$ and $\mathrm{C}$, albumin, thiols, $\beta$-carotenes, etc.) [59-62].

One of the most important antioxidant enzymes is SOD, which catalyzes $\mathrm{O}_{2}^{-}$into oxygen and $\mathrm{H}_{2} \mathrm{O}_{2}[63,64]$. SOD2 stands up against mitochondrial ROS and can minimalize vascular calcification among VSMC [65, 66]. In male and female patients with idiopathic pulmonary arterial hypertension, the expressions of all three SOD isoforms were reduced compared to the healthy patients [67]. Nevertheless, gene rs 7655372 locus polymorphism of SOD3 in male and female patients is a risk factor for ischemic stroke [68]. The association between SODs activities and vascular diseases is imperative for developing a new diagnostic biomarker and therapy strategy.

Regulation of CAT implicates OxS-associated pathways and diverse transcription factors, for instance, nuclear factor Y (NF-Y), peroxisome proliferator-activated receptor $\delta$ (PPAR $\delta$ ), specificity protein 1 (Sp1), etc. [69-72]. CAT protective role versus ROS is established, and according to some authors, reduction of CAT activity enhances abdominal aortic dilatation appearance [73]. Further, cardiac CAT activation by adipokine apelin during hypertrophic remodeling manifests protective features versus ROS in male C57BL6/J mice and cultures of cardiac myocytes [74]. Similarly, in experimental male rats, CAT reactivation by curcumin in the heart and aorta displays protective properties against lipopolysaccharide [75]. In addition, results from Dai et al. [76] study showed that CAT upregulation in mitochondria protects male and female mice from vascular aging.

Another intracellular antioxidant enzyme, GPx1, transforms $\mathrm{H}_{2} \mathrm{O}_{2}$ to $\mathrm{H}_{2} \mathrm{O}$ and lipid peroxides to alcohols

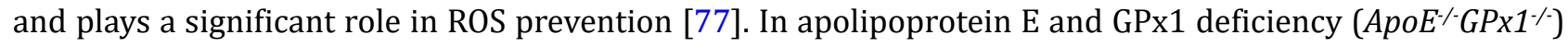
female mice, atherosclerosis and plaque lesions were more expressed than those without $G P x 1^{1}$ [78]. The same authors declared that $G P x 1 \%$ causes ROS elevation in the aorta of the animals [78]. In another animal study with male $A p o E^{-/}$mice overexpressing GPx4, atherosclerosis progression and lipid peroxidation were suppressed in aorta endothelial cells [79]. According to new data, GPx1 protein expression was significantly reduced in male mice aortic tissue with induced diabetes [80]. GR also manifests a protective feature against $\mathrm{OxS}$, and its overexpression in heart tissue of a Klotho-hypomorphic (antiaging gene) deficient male mice resulted in heart failure and apoptotic prevention [81]. GSH has a significant part in the antioxidant defense system and cell homeostasis and metabolism. Nevertheless, GSH deficiency has an essential part of aging and cardiovascular pathology [82].

\section{Antioxidants on vascular diseases}

Although data from studies with experimental animal models advocate the protective role of antioxidants versus vascular disorders [83-86], data from clinical trials are not conclusive [56, 87]. For example, vitamin A has been rated as a beneficial supplement that may reduce $0 \mathrm{xS}$ in diabetic individuals with ischemic heart disease [88]. Melatonin supplementation may reduce myocardial ischemic-reperfusion injury in male and female patients undergoing coronary artery bypass [89]. Further, vitamins E, A, and C decrease blood pressure in male patients with hypertension [90]. Consistent with these statements, a new meta-analysis 
that included 11 cross-sectional studies and 7 case-control studies with both gender individuals concluded that vitamin C positively influences blood pressure and endothelial function [91]. Still, long-term trials with an extensive number of participants are necessary for clarification of vitamin $C$ benefit role in cardiac complications [92, 93]. A large randomization study indicated that vitamin E supplementation at high doses might even elevate the risk for coronary artery disease development [94]. Indeed, treatment with vitamin $\mathrm{E}$ for an extended time did not affect vascular events in male and female individuals with diabetes or other cardiovascular comorbidities [95]. Micronutrient selenium, which is considered a potent antioxidant, failed to reduce chronic chagasic cardiomyopathy in 66 male and female patients, according to a randomized, placebo-controlled, double-blinded clinical trial [96]. Ye et al. [97] analyzed data from 15 trials and 188,209 participants and revealed that vitamins $C$ and $E$, together with $\beta$ carotene, had no positive impact on cardiovascular complications. It cannot be denied that reducing $0 x S$ via antioxidants is important; however, up to now, the results of clinical studies have been predominantly pessimistic [98]. We assume that there are several reasons for this attitude. Most of the clinical trials regarding vascular comorbidities have been examined a single antioxidant, so antioxidant combinations and their molecular basis might be discussed in future investigations [3]. Secondly, OxS should be identified through enzymes activity rather than produced molecules [98].

\section{Conclusion}

The impact of OxS is detrimental to human health, and numerous studies confirmed that high ROS production contributes to the initiation and progression of CVD [5, 99, 100]. Thus, the antioxidant defense has an essential role in the homeostatic functioning of the vascular endothelial system, whereby antioxidant enzymes represent the primary line of antioxidant protection [4, 59]. Numerous studies have proven the association between reduced expression and activity of antioxidant enzymes and CVD development $[68,73,80]$. Hence, additional research on how ROS is utilized in the cardiovascular system and consequently impacts the regulation of antioxidant enzymes is needed to develop new diagnostic biomarkers and therapeutic strategies.

\section{Abbreviations}

CAT: catalase

$\mathrm{Cu}$ : copper

CVD: cardiovascular disease

GPx: glutathione peroxidase

GR: glutathione reductase

GSH: glutathione

$\mathrm{H}_{2} \mathrm{O}_{2}$ : hydrogen peroxide

$\mathrm{Mn}$ : manganese

NAD(P)H: nicotinamide adenine dinucleotide phosphate

NO: nitric oxide

$\mathrm{O}_{2}:$ superoxide anion

ONOO: peroxynitrite

OxS: oxidative stress

RNS: reactive nitrogen species

ROS: reactive oxygen species

SOD: superoxide dismutase

XO: xanthine oxidase

Zn: zinc 


\section{Declarations}

Author contributions

JR and KB wrote the manuscript and contributed conception. ERI and MO designed, wrote, and supervised the manuscript. All authors contributed to manuscript revision, read and approved the submitted version.

\section{Conflicts of interest}

The authors declare that they have no conflicts of interest.

\section{Ethical approval}

Not applicable.

\section{Consent to participate}

Not applicable.

\section{Consent to publication}

Not applicable.

\section{Availability of data and materials}

Not applicable.

\section{Funding}

This work was funded by the Ministry of Education, Science and Technological Development of the Republic of Serbia (Contract No\#451-03-9/2021-14/200017). The funders had no role in study design, data collection and analysis, decision to publish, or preparation of the manuscript.

\section{Copyright}

(C) The Author(s) 2021.

\section{References}

1. Madamanchi NR, Vendrov A, Runge MS. Oxidative stress and vascular disease. Arterioscler Thromb Vasc Biol. 2005;25:29-38.

2. Sena CM, Leandro A, Azul L, Seiça R, Perry G. Vascular oxidative stress: impact and therapeutic approaches. Front Physiol. 2018;9:1668.

3. Haidara M, Mikhailidis DP, Yassin HZ, Dobutovic B, Smiljanic KT, Soskic S, et al. Evaluation of the possible contribution of antioxidants administration in metabolic syndrome. Curr Pharm Des. 2011;17:3699-712.

4. Obradovic M, Essack M, Zafirovic S, Sudar-Milovanovic E, Bajic VP, Van Neste C, et al. Redox control of vascular biology. Biofactors. 2020;46:246-62.

5. Pizzino G, Irrera N, Cucinotta M, Pallio G, Mannino F, Arcoraci V, et al. Oxidative stress: harms and benefits for human health. Oxid Med Cell Longev. 2017;2017:8416763.

6. Bajić V, Spremo-Potparević B, Živković L, Čabarkapa A, Kotur-Stevuljević J, Isenović E, et al. Surface-modified $\mathrm{TiO}_{2}$ nanoparticles with ascorbic acid: antioxidant properties and efficiency against DNA damage in vitro. Colloids Surf B Biointerfaces. 2017;155:323-31.

7. Rizzo M, Abate N, Chandalia M, Rizvi AA, Giglio RV, Nikolic D, et al. Liraglutide reduces oxidative stress and restores heme oxygenase- 1 and ghrelin levels in patients with type 2 diabetes: a prospective pilot study. J Clin Endocrinol Metab. 2015;100:603-6.

8. Chen $\mathrm{Q}$, Wang $\mathrm{Q}$, Zhu J, Xiao $\mathrm{Q}$, Zhang L. Reactive oxygen species: key regulators in vascular health and diseases. Br J Pharmacol. 2018;175:1279-92. 
9. Essack M, Salhi A, Stanimirovic J, Tifratene F, Bin Raies A, Hungler A, et al. Literature-based enrichment insights into redox control of vascular biology. Oxid Med Cell Longev. 2019;2019:1769437.

10. Radak D, Resanovic I, Isenovic ER. Link between oxidative stress and acute brain ischemia. Angiology. 2014;65:667-76.

11. Lubrano V, Balzan S. Enzymatic antioxidant system in vascular inflammation and coronary artery disease. World J Exp Med. 2015;5:218-24.

12. Liguori I, Russo G, Curcio F, Bulli G, Aran L, Della-Morte D, et al. Oxidative stress, aging, and diseases. Clin Interv Aging. 2018;13:757-72.

13. Jozanov-Stankov O, Đurić J, Dobutovic B, Isenovic ER. Determination of total antioxidant status (TAS) as a biochemical parameter in control of workers' health. Arch Biol Sci. 2009;61:375-82.

14. Wu L, Noyan Ashraf MH, Facci M, Wang R, Paterson PG, Ferrie A, et al. Dietary approach to attenuate oxidative stress, hypertension, and inflammation in the cardiovascular system. Proc Natl Acad Sci U S A. 2004;101:7094-9.

15. Obradovic M, Bogdanovic N, Stanimirovic J, Unic-Stojanovic D, Radak DJ, Isenovic ER. Hypothesis related to the regulation of inducible nitric oxide synthase during carotid endarterectomy. Med Hypotheses. 2019;122:16-8.

16. Kaur K, Bedi G, Kaur M, Vij A, Kaur I. Lipid peroxidation and the levels of antioxidant enzymes in coronary artery disease. Indian J Clin Biochem. 2008;23:33-7.

17. Bajic VP, Van Neste C, Obradovic M, Zafirovic S, Radak D, Bajic VB, et al. Glutathione "redox homeostasis" and its relation to cardiovascular disease. Oxid Med Cell Longev. 2019;2019:5028181.

18. Lei XG, Zhu JH, Cheng WH, Bao Y, Ho YS, Reddi AR, et al. Paradoxical roles of antioxidant enzymes: basic mechanisms and health implications. Physiol Rev. 2016;96:307-64.

19. Johnson F, Giulivi C. Superoxide dismutases and their impact upon human health. Mol Aspects Med. 2005;26:340-52.

20. Zelko IN, Mariani TJ, Folz RJ. Superoxide dismutase multigene family: a comparison of the CuZn-SOD (SOD1), Mn-SOD (SOD2), and EC-SOD (SOD3) gene structures, evolution, and expression. Free Radic Biol Med. 2002;33:337-49.

21. Vucić V, Isenović ER, Adzić M, Ruzdijić S, Radojcić MB. Effects of gamma-radiation on cell growth, cycle arrest, death, and superoxide dismutase expression by DU 145 human prostate cancer cells. Braz J Med Biol Res. 2006;39:227-36.

22. Fischer LR, Igoudjil A, Magrané J, Li Y, Hansen JM, Manfredi G, et al. SOD1 targeted to the mitochondrial intermembrane space prevents motor neuropathy in the Sod1 knockout mouse. Brain. 2011;134:196-209.

23. Flynn JM, Melov S. SOD2 in mitochondrial dysfunction and neurodegeneration. Free Radic Biol Med. 2013;62:4-12.

24. Cramer-Morales K, Heer CD, Mapuskar KA, Domann FE. SOD2 targeted gene editing by CRISPR/Cas9 yields human cells devoid of MnSOD. Free Radic Biol Med. 2015;89:379-86.

25. Lebovitz RM, Zhang H, Vogel H, Cartwright J Jr, Dionne L, Lu N, et al. Neurodegeneration, myocardial injury, and perinatal death in mitochondrial superoxide dismutase-deficient mice. Proc Natl Acad Sci U S A. 1996;93:9782-7.

26. Maksimenko AV, Vavaev AV. Antioxidant enzymes as potential targets in cardioprotection and treatment of cardiovascular diseases. Enzyme antioxidants: the next stage of pharmacological counterwork to the oxidative stress. Heart Int. 2012;7:e3.

27. Kaushal J, Mehandia S, Singh G, Raina A, Arya SK. Catalase enzyme: application in bioremediation and food industry. Biocatal Agric Biotechnol. 2018;16:192-9. 
28. Glorieux C, Calderon PB. Catalase, a remarkable enzyme: targeting the oldest antioxidant enzyme to find a new cancer treatment approach. Biol Chem. 2017;398:1095-108.

29. Góth L, Rass P, Páy A. Catalase enzyme mutations and their association with diseases. Mol Diagn. 2004;8:141-9.

30. Margis R, Dunand C, Teixeira FK, Margis-Pinheiro M. Glutathione peroxidase family-an evolutionary overview. FEBS J. 2008;275:3959-70.

31. Couto N, Wood J, Barber J. The role of glutathione reductase and related enzymes on cellular redox homoeostasis network. Free Radic Biol Med. 2016;95:27-42.

32. Blankenberg S, Rupprecht HJ, Bickel C, Torzewski M, Hafner G, Tiret L, et al; AtheroGene Investigators. Glutathione peroxidase 1 activity and cardiovascular events in patients with coronary artery disease. N Engl J Med. 2003;349:1605-13.

33. Dubois-Deruy E, Peugnet V, Turkieh A, Pinet F. Oxidative stress in cardiovascular diseases. Antioxidants (Basel). 2020;9:864.

34. Tsutsui H, Kinugawa S, Matsushima S. Mitochondrial oxidative stress and dysfunction in myocardial remodelling. Cardiovasc Res. 2009;81:449-56.

35. Sack MN, Fyhrquist FY, Saijonmaa OJ, Fuster V, Kovacic JC. Basic biology of oxidative stress and the cardiovascular system: part 1 of a 3-part series. J Am Coll Cardiol. 2017;70:196-211.

36. Craige SM, Kant S, Keaney JF Jr. Reactive oxygen species in endothelial function-from disease to adaptation-. Circ J. 2015;79:1145-55.

37. Obradovic M, Bogdanovic N, Radak D, Isenovic ER. Editorial: oxidative stress in pathophysiological conditions. Curr Vasc Pharmacol. 2015;13:226-8.

38. Tsuchihashi T. Which is more important, xanthine oxidase activity or uric acid itself, in the risk for cardiovascular disease? Hypertens Res. 2021;44:1543-5.

39. Feoli AM, Macagnan FE, Piovesan CH, Bodanese LC, Siqueira IR. Xanthine oxidase activity is associated with risk factors for cardiovascular disease and inflammatory and oxidative status markers in metabolic syndrome: effects of a single exercise session. Oxid Med Cell Longev. 2014;2014:587083.

40. Takaishi K, Kinoshita H, Kawashima S, Kawahito S. Human vascular smooth muscle function and oxidative stress induced by NADPH oxidase with the clinical implications. Cells. 2021;10:1947.

41. Cross AR, Segal AW. The NADPH oxidase of professional phagocytes-prototype of the NOX electron transport chain systems. Biochim Biophys Acta. 2004;1657:1-22.

42. Poznyak AV, Grechko AV, Orekhova VA, Khotina V, Ivanova EA, Orekhov AN. NADPH oxidases and their role in atherosclerosis. Biomedicines. 2020;8:206.

43. Lee MY, San Martin A, Mehta PK, Dikalova AE, Garrido AM, Datla SR, et al. Mechanisms of vascular smooth muscle NADPH oxidase 1 (Nox1) contribution to injury-induced neointimal formation. Arterioscler Thromb Vasc Biol. 2009;29:480-7.

44. Vendrov AE, Hakim ZS, Madamanchi NR, Rojas M, Madamanchi C, Runge MS. Atherosclerosis is attenuated by limiting superoxide generation in both macrophages and vessel wall cells. Arterioscler Thromb Vasc Biol. 2007;27:2714-21.

45. Gluvic Z, Obradovic M, Lackovic M, Samardzic V, Tica Jevtic J, Essack M, et al. HbA1C as a marker of retrograde glycaemic control in diabetes patient with co-existed beta-thalassaemia: a case report and a literature review. J Clin Pharm Ther. 2020;45:379-83.

46. Saito H, Tanaka K, Iwasaki T, Oda A, Watanabe S, Kanno M, et al. Xanthine oxidase inhibitors are associated with reduced risk of cardiovascular disease. Sci Rep. 2021;11:1380.

47. Laksono AB, Kusumawati R, Suselo YH, Indarto D. In silico development of new candidate of NADPH oxidase inhibitor for hypertension treatment. IOP Conf Ser: Earth Environ Sci. 2021;819:012071. 
48. Panday A, Sahoo MK, Osorio D, Batra S. NADPH oxidases: an overview from structure to innate immunity-associated pathologies. Cell Mol Immunol. 2015;12:5-23.

49. Incalza MA, D'Oria R, Natalicchio A, Perrini S, Laviola L, Giorgino F. Oxidative stress and reactive oxygen species in endothelial dysfunction associated with cardiovascular and metabolic diseases. Vascul Pharmacol. 2018;100:1-19.

50. Obradovic M, Zafirovic S, Essack M, Dimitrov J, Zivkovic L, Spremo-Potparevic B, et al. Antioxidant enzymes expression in lymphocytes of patients undergoing carotid endarterectomy. Med Hypotheses. 2020;134:109419.

51. Landmesser U, Dikalov S, Price SR, McCann L, Fukai T, Holland SM, et al. Oxidation of tetrahydrobiopterin leads to uncoupling of endothelial cell nitric oxide synthase in hypertension. J Clin Invest. 2003;111:1201-9.

52. Liaudet L, Vassalli G, Pacher P. Role of peroxynitrite in the redox regulation of cell signal transduction pathways. Front Biosci (Landmark Ed). 2009;14:4809-14.

53. Alhayaza R, Haque E, Karbasiafshar C, Sellke FW, Abid MR. The relationship between reactive oxygen species and endothelial cell metabolism. Front Chem. 2020;8:592688.

54. Peoples JN, Saraf A, Ghazal N, Pham TT, Kwong JQ. Mitochondrial dysfunction and oxidative stress in heart disease. Exp Mol Med. 2019;51:1-13.

55. Ide T, Tsutsui H, Hayashidani S, Kang D, Suematsu N, Nakamura K, et al. Mitochondrial DNA damage and dysfunction associated with oxidative stress in failing hearts after myocardial infarction. Circ Res. 2001;88:529-35.

56. Mohamed AH, Hanaa ZY, Zorica Z, Dimitri PM, Esma RI. Diabetes and antioxidants: myth or reality? Curr Vasc Pharmacol. 2010;8:661-72.

57. Bravo-Sánchez E, Peña-Montes D, Sánchez-Duarte S, Saavedra-Molina A, Sánchez-Duarte E, Montoya-Pérez R. Effects of apocynin on heart muscle oxidative stress of rats with experimental diabetes: implications for mitochondria. Antioxidants (Basel). 2021;10:335.

58. Antioxidants: principles and applications. In: Shahidi F, editor. Handbook of antioxidants for food preservation. Woodhead Publishing; 2015. pp. 1-14.

59. Matés JM, Pérez-Gómez C, Núñez de Castro I. Antioxidant enzymes and human diseases. Clin Biochem. 1999;32:595-603.

60. Irato P, Santovito G. Enzymatic and non-enzymatic molecules with antioxidant function. Antioxidants (Basel). 2021;10:579.

61. Dobutovic B, Sudar E, Tepavcevic S, Djordjevic J, Djordjevic A, Radojcic M, et al. Effects of ghrelin on protein expression of antioxidative enzymes and iNOS in the rat liver. Arch Med Sci. 2014;10:806-16.

62. Nikolic D, Stanimirovic J, Bjelogrlic P, Isenovic ER. Oxidative stress and the role of antioxidative treatment in diabetes mellitus. Oxid Antioxid Med Sci. 2014;3:9.

63. Martínez-Rey D, Carmona-Rodríguez L, Fernández-Aceñero MJ, Mira E, Mañes S. Extracellular superoxide dismutase, the endothelial basement membrane, and the WNT pathway: new players in vascular normalization and tumor infiltration by T-cells. Front Immunol. 2020;11:579552.

64. Jones DP. Redefining oxidative stress. Antioxid Redox Signal. 2006;8:1865-79.

65. Tsai YT, Yeh HY, Chao CT, Chiang CK. Superoxide dismutase 2 (SOD2) in vascular calcification: a focus on vascular smooth muscle cells, calcification pathogenesis, and therapeutic strategies. Oxid Med Cell Longev. 2021;2021:6675548.

66. Andújar-Vera F, García-Fontana C, Lozano-Alonso S, González-Salvatierra S, Iglesias-Baena I, Muñoz-Torres $\mathrm{M}$, et al. Association between oxidative-stress-related markers and calcified femoral artery in type 2 diabetes patients. J Pharm Biomed Anal. 2020;190:113535. 
67. Zhang R, Wang L, Zhao QH, Jiang R, Gong SG, Jiang X, et al. Alteration of extracellular superoxide dismutase in idiopathic pulmonary arterial hypertension. Front Med (Lausanne). 2020;7:509.

68. Yang X, Yang S, Xu H, Liu D, Zhang Y, Wang G. Superoxide dismutase gene polymorphism is associated with ischemic stroke risk in the China Dali region Han population. Neurologist. 2021;26:27-31.

69. Hwang JS, Hur J, Lee WJ, Won JP, Lee HG, Lim DS, et al. Catalase mediates the inhibitory actions of PPAR $\delta$ against angiotensin II-triggered hypertrophy in H9c2 cardiomyocytes. Antioxidants (Basel). 2021;10:1223.

70. Tan WQ, Wang K, Lv DY, Li PF. Foxo3a inhibits cardiomyocyte hypertrophy through transactivating catalase. J Biol Chem. 2008;283:29730-9.

71. Okuno Y, Matsuda M, Miyata Y, Fukuhara A, Komuro R, Shimabukuro M, et al. Human catalase gene is regulated by peroxisome proliferator activated receptor-gamma through a response element distinct from that of mouse. Endocr J. 2010;57:303-9.

72. Nenoi M, Ichimura S, Mita K, Yukawa O, Cartwright IL. Regulation of the catalase gene promoter by Sp1, CCAAT-recognizing factors, and a WT1/Egr-related factor in hydrogen peroxide-resistant HP100 cells. Cancer Res. 2001;61:5885-94.

73. Parastatidis I, Weiss D, Joseph G, Taylor WR. Overexpression of catalase in vascular smooth muscle cells prevents the formation of abdominal aortic aneurysms. Arterioscler Thromb Vasc Biol. 2013;33:2389-96.

74. Foussal C, Lairez O, Calise D, Pathak A, Guilbeau-Frugier C, Valet P, et al. Activation of catalase by apelin prevents oxidative stress-linked cardiac hypertrophy. FEBS Lett. 2010;584:2363-70.

75. Ahmadabady S, Beheshti F, Shahidpour F, Khordad E, Hosseini M. A protective effect of curcumin on cardiovascular oxidative stress indicators in systemic inflammation induced by lipopolysaccharide in rats. Biochem Biophys Rep. 2021;25:100908.

76. Dai DF, Santana LF, Vermulst M, Tomazela DM, Emond MJ, MacCoss MJ, et al. Overexpression of catalase targeted to mitochondria attenuates murine cardiac aging. Circulation. 2009;119:2789-97.

77. Flohé L. Glutathione peroxidase. Basic Life Sci. 1988;49:663-8.

78. Torzewski M, Ochsenhirt V, Kleschyov AL, Oelze M, Daiber A, Li H, et al. Deficiency of glutathione peroxidase-1 accelerates the progression of atherosclerosis in apolipoprotein E-deficient mice. Arterioscler Thromb Vasc Biol. 2007;27:850-7.

79. Guo Z, Ran Q, Roberts LJ 2nd, Zhou L, Richardson A, Sharan C, et al. Suppression of atherogenesis by overexpression of glutathione peroxidase-4 in apolipoprotein E-deficient mice. Free Radic Biol Med. 2008;44:343-52.

80. Fang X, Liu L, Zhou S, Zhu M, Wang B. N-acetylcysteine inhibits atherosclerosis by correcting glutathione-dependent methylglyoxal elimination and dicarbonyl/oxidative stress in the aorta of diabetic mice. Mol Med Rep. 2021;23:201.

81. Chen K, Wang S, Sun QW, Zhang B, Ullah M, Sun Z. Klotho deficiency causes heart aging via impairing the Nrf2-GR pathway. Circ Res. 2021;128:492-507.

82. Matuz-Mares D, Riveros-Rosas H, Vilchis-Landeros MM, Vázquez-Meza H. Glutathione participation in the prevention of cardiovascular diseases. Antioxidants (Basel). 2021;10:1220.

83. Mazzone G, Morisco C, Lembo V, D’Argenio G, D’Armiento M, Rossi A, et al. Dietary supplementation of vitamin $D$ prevents the development of western diet-induced metabolic, hepatic and cardiovascular abnormalities in rats. United European Gastroenterol J. 2018;6:1056-64.

84. Farhangi MA, Nameni G, Hajiluian G, Mesgari-Abbasi M. Cardiac tissue oxidative stress and inflammation after vitamin D administrations in high fat- diet induced obese rats. BMC Cardiovasc Disord. 2017;17:161.

85. Huwait EA, Al-Ghamdi MA. Protective role of carnitine synergized with vitamin E against isoproterenol induced cardiac infarction in rats. Afr J Tradit Complement Altern Med. 2017;14:25-32. 
86. Haidara MA, Khloussy H, Ammar H, Aal Kassem LA. Impact of alpha-tocopherol and vitamin $\mathrm{C}$ on endothelial markers in rats with streptozotocin-induced diabetes. Med Sci Monit. 2004;10:BR41-6.

87. Shah AK, Dhalla NS. Effectiveness of some vitamins in the prevention of cardiovascular disease: a narrative review. Front Physiol. 2021;12:729255.

88. Altoum AEA, Osman AL, Babker AM. Comparative study of levels of selective oxidative stress markers (malondialdehyde, zinc, and antioxidant vitamins $\mathrm{A}, \mathrm{E}$, and $\mathrm{C}$ ) in ischemic and non-ischemic heart disease patients suffering from type-2 diabetes. Asian J Pharm Clin Res. 2018;11:508-10.

89. Dwaich KH, Al-Amran FG, Al-Sheibani BI, Al-Aubaidy HA. Melatonin effects on myocardial ischemia-reperfusion injury: impact on the outcome in patients undergoing coronary artery bypass grafting surgery. Int J Cardiol. 2016;221:977-86.

90. Rodrigo R, Prat H, Passalacqua W, Araya J, Bächler JP. Decrease in oxidative stress through supplementation of vitamins $\mathrm{C}$ and $\mathrm{E}$ is associated with a reduction in blood pressure in patients with essential hypertension. Clin Sci (Lond). 2008;114:625-34.

91. Ran L, Zhao W, Tan X, Wang H, Mizuno K, Takagi K, et al. Association between serum vitamin $\mathrm{C}$ and the blood pressure: a systematic review and meta-analysis of observational studies. Cardiovasc Ther. 2020;2020:4940673.

92. Mason SA, Keske MA, Wadley GD. Effects of vitamin C supplementation on glycemic control and cardiovascular risk factors in people with type 2 diabetes: a GRADE-assessed systematic review and meta-analysis of randomized controlled trials. Diabetes care. 2021;44:618-30.

93. Barteková M, Adameová A, Görbe A, Ferenczyová K, Pecháňová O, Lazou A, et al. Natural and synthetic antioxidants targeting cardiac oxidative stress and redox signaling in cardiometabolic diseases. Free Radic Biol Med. 2021;169:446-77.

94. Wang T, Xu L. Circulating vitamin E levels and risk of coronary artery disease and myocardial infarction: a mendelian randomization study. Nutrients. 2019;11:2153.

95. Heart Outcomes Prevention Evaluation Study Investigators; Yusuf S, Dagenais G, Pogue J, Bosch J, Sleight P. Vitamin E supplementation and cardiovascular events in high-risk patients. N Engl J Med. 2000;342:154-60.

96. Holanda MT, Mediano MFF, Hasslocher-Moreno AM, Gonzaga BMS, Carvalho ACC, Ferreira RR, et al. Effects of selenium treatment on cardiac function in Chagas heart disease: results from the STCC randomized Trial. EClinicalMedicine. 2021;40:101105.

97. Ye Y, Li J, Yuan Z. Effect of antioxidant vitamin supplementation on cardiovascular outcomes: a meta-analysis of randomized controlled trials. PloS One. 2013;8:e56803.

98. Cammisotto V, Nocella C, Bartimoccia S, Sanguigni V, Francomano D, Sciarretta S, et al. The role of antioxidants supplementation in clinical practice: focus on cardiovascular risk factors. Antioxidants (Basel). 2021;10:146.

99. Izzo C, Vitillo P, Di Pietro P, Visco V, Strianese A, Virtuoso N, et al. The role of oxidative stress in cardiovascular aging and cardiovascular diseases. Life (Basel). 2021;11:60.

100. Daiber A, Hahad O, Andreadou I, Steven S, Daub S, Münzel T. Redox-related biomarkers in human cardiovascular disease-classical footprints and beyond. Redox Biol. 2021;42:101875. 